\title{
ANALISIS TATA LETAK RECLOSER MENGGUNAKAN METODE PENELETIAN STATISTIKA BEBAN DAN POPULASI GUNA MEMAKSIMALKAN KINERJA SISTEM
}

\author{
Farda Akhyal Adiba1, Zainal Abidin ${ }^{2}$, Suharijanto ${ }^{3}$ \\ ${ }^{1)}$ Program Studi Teknik Elektro, Fakultas Teknik, Universitas Islam LamonganI \\ ${ }^{2,3)}$ Dosen Jurusan Teknik Elektro, Fakultas Teknik, Universitas Islam Lamongan ${ }^{2,3}$ \\ E-mail : farda.alakhya@gmail.com ${ }^{1}$,inal9474@gmail.com² ${ }^{2} \underline{\text { suharijanto2014@gmail.com }}{ }^{3}$
}

\begin{abstract}
Disturbance at PT. PLN (Persero) Rayon Sidayu Area Gresik Distribution East Java is quite diverse, most of the disturbance that occurred was temporary temporary, the cause is not known and to minimize the disturbance is widely used automatic cover (recloser) on the electricity distribution network. The placement of the recloser is only based on a safe distance without consideration of the load and the customer population and calculation of the layout for the determination of the location that can maximize the system performance. By knowing the burden and the customer population it will be able to know how many losses and the number of customers who will experience a disruption when the recloser has failed function due to improper layout, load and customer population can also be a variable to calculate SAIFI value. One parameter of failure (the extent of failure or blackout to the customer) in the electrical world is the value of SAIFI (System Average Interruption Frequency Index). Higher values indicate an increasing rate of failure. In this analysis there are 3 points that counted SAIFInya value that is point 19 with SAIFI value 15.1, point 18 with SAIFI value 61,7 and point 12 with value SAIFI 137,2. from the calculation of each point can get the result of SAIFI minimum disturbance index that is at point 19.
\end{abstract}

Keywords: Temporary Disorder, Auto Cover (Recloser), Burden and Population, Variable, SAIFI

\section{PENDAHULUAN}

Perkembangan Teknologi Informasi yang pesat di Era Globalisasi ini memberikan segala kemudahan bagi manusia untuk beraktifitas, namun untuk mengakses segala kemudahan tersebut di butuhkan pasokan energi listrik yang besar dan setabil.

Ketergantungan atas energi listrik yang besar dan setabil ini cukup bisa di atasi oleh penyedia listrik saat ini, namun banyak sekali gangguan yang menyebabkan putusnya energi listrik tersebut, akibatnya adalah terhentinya akses teknologi dan informasi yang dapat merugikan pengguna dan penyedia teknologi dan informasi tersebut.

Ditemukanya Recloser memberikan dampak yang luar biasa sebagai salah satu solusi dari gangguan putusnya energi listrik, karena recloser dapat memisahkan daerah atau jaringan yang terganggu sistemnya secara cepat sehingga dapat memperkecil daerah yang terganggu pada gangguan sesaat, recloser akan memisahkan daerah gangguan secara sesaat sampai gangguan tersebut akan dianggap hilang, dengan demikian recloser akan masuk kembali sesuai settingannya sehingga jaringan akan aktif kembali secara otomatis.

Namun pemasangan recloser selama ini hanya berdasarkan jarak aman antara suatu recloser dengan komponen pemutus lainnya dan belum mempertimbangkan daerah yang memiliki konsumsi beban dan populasi pelanggan yang tinggi, Berdasarkan data parameter kinerja recloser dan lokasi penempatan recloser dilakukan perhitungan besarnya beban dan populasi dari tiap-tiap lokasi penempatan recloser sehingga diperoleh hasil yang maksimal. Dari hasil perhitungan tersebut dapat digunakan sebagai dasar analisia tata letak recloser dengan metode peneletian statistika guna memaksimalkan kinerja sistem. 


\section{METODELOGI PENELITIAN}

\section{Flowchart Penelitian}

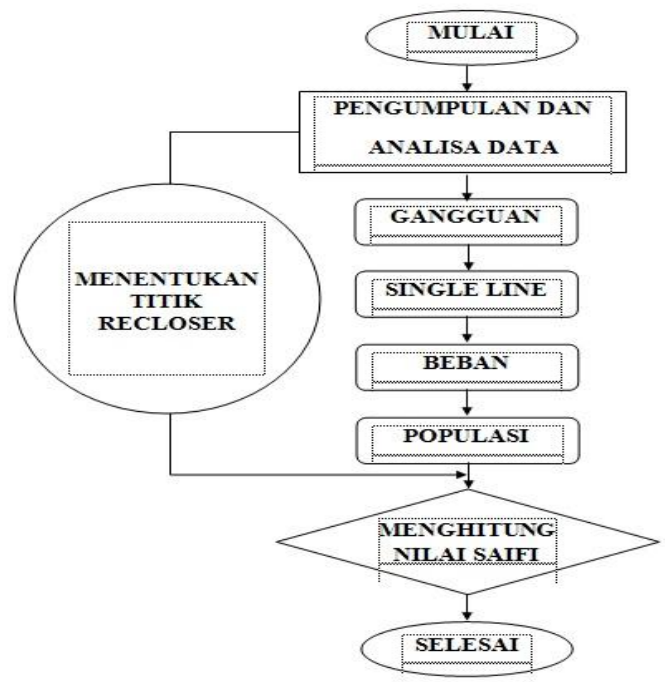

Gambar 1. Diagram Alir Penelitian

\section{PEMBAHASAN}

Langkah pertama dalam peneltian ini adalah mencari data gangguan pada PLN
(Persero) Gresik Rayon Sidayu agar dapat diketahui jumlah gangguan perbulan dan pertahun.

Tabel 1. Gangguan Tiap Tahun

\begin{tabular}{clccc}
\hline \multirow{2}{*}{ No. } & \multirow{2}{*}{ Bulan } & \multicolumn{2}{c}{ Gangguan } & \multirow{2}{*}{ JML } \\
\cline { 3 - 4 } & & Permanen & Temporer & \\
\hline 1. & April & 1 & 3 & 4 \\
\hline 2. & Mei & 1 & 0 & 1 \\
\hline 3. & Juni & 2 & 2 & 4 \\
\hline 4. & Juli & 4 & 1 & 5 \\
\hline 5. & Agustus & 1 & 2 & 3 \\
\hline 6. & Oktober & 0 & 1 & 1 \\
\hline 7. & September & 0 & 2 & 2 \\
\hline & Jumlah & 9 & 11 & 20 \\
\hline
\end{tabular}

Setelah mendapatkan data gangguan lalu dilakukan observasi yang menjelaskan bahwa recloser belum dapat melaksanakan tugas dengan maksimal sebagi sistem proteksi, keudian di cari penyebab kurang dapatnya recloser dalam melakukan proteksi dengan Melihat data Single Line.

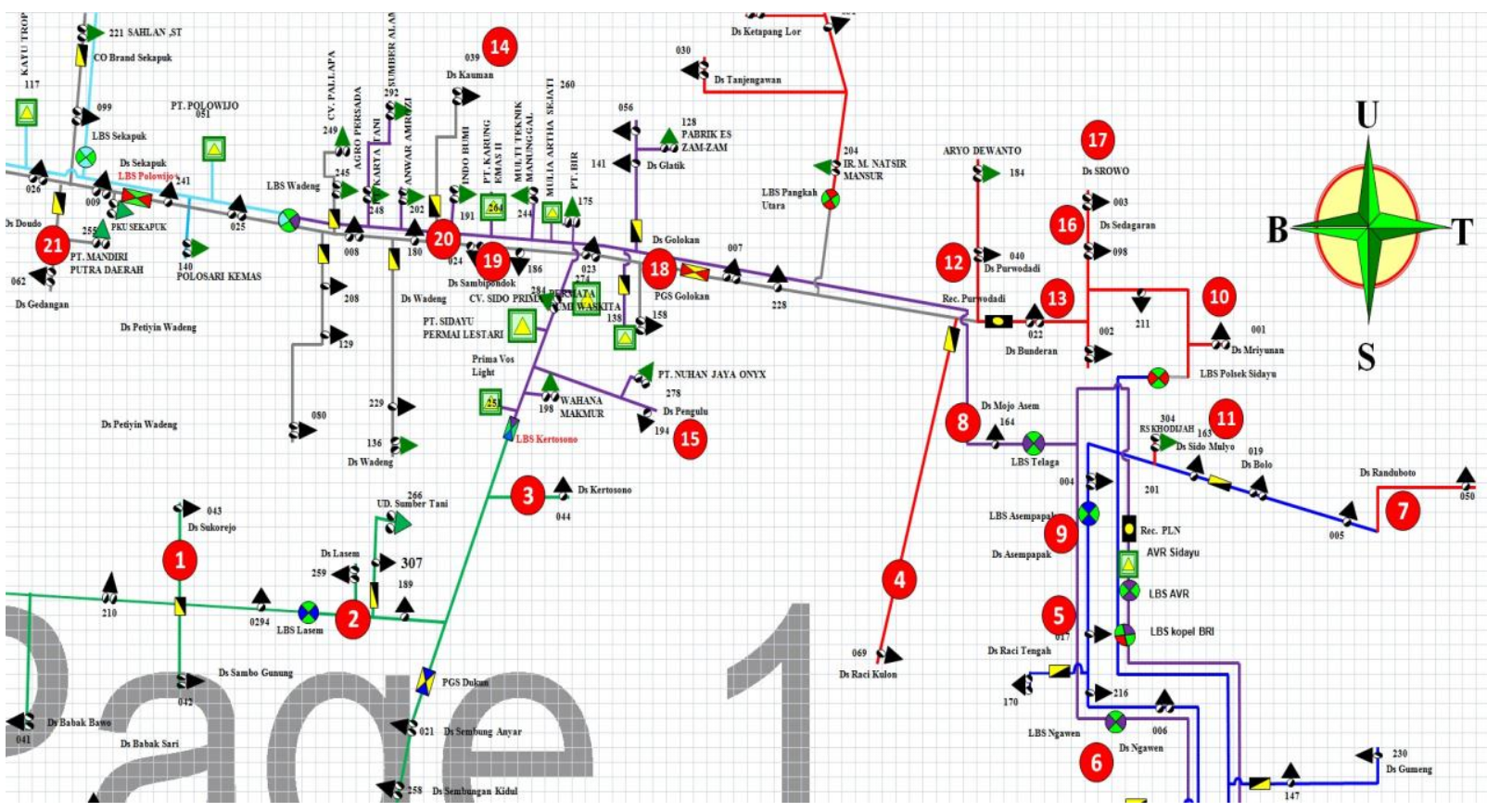

Gambar 2. Single Line Kecamatan Sidayu

Setelah mengobservasi dan menyimpulkan data single line kemudian dicari data pengguna listrik sebagai data beban agar dapat mengetahui berapa besar kerugian penggunaan daya ketika recloser gagal berfngsi dengan baik. 
Tabel 2. Pengguna Beban Kecamatan Sidayu

\begin{tabular}{|c|c|c|c|c|c|}
\hline \multirow{2}{*}{$\mathrm{N}$} & \multirow{2}{*}{ Desa } & \multicolumn{3}{|c|}{ Daya Yang Di Pakai } & \multirow{2}{*}{$\mathrm{Jml}$} \\
\hline & & $450 \mathrm{VA}$ & $900 \mathrm{VA}$ & 1300VA & \\
\hline 1 & Sukorejo & 344 & 431 & 384 & 1159 \\
\hline 2 & Lasem & 467 & 546 & 356 & 1369 \\
\hline 3 & Kertosono & 455 & 545 & 335 & 1335 \\
\hline 4 & $\begin{array}{l}\text { Raci } \\
\text { Kulon }\end{array}$ & 104 & 173 & 87 & 364 \\
\hline 5 & $\begin{array}{l}\text { Raci } \\
\text { Tengah }\end{array}$ & 299 & 173 & 261 & 733 \\
\hline 6 & Ngawen & 423 & 480 & 336 & 1239 \\
\hline 7 & Randuboto & 643 & 731 & 505 & 1879 \\
\hline 8 & $\begin{array}{l}\text { Mojo } \\
\text { Asem }\end{array}$ & 125 & 93 & 81 & 299 \\
\hline 9 & $\begin{array}{l}\text { Asem } \\
\text { Papak }\end{array}$ & 190 & 266 & 183 & 639 \\
\hline 10 & Miriyunan & 430 & 360 & 289 & 1079 \\
\hline 11 & $\begin{array}{l}\text { Sido } \\
\text { Mulyo } \\
\end{array}$ & 173 & 167 & 165 & 505 \\
\hline 12 & Purwodadi & 348 & 420 & 248 & 1016 \\
\hline 13 & Bunderan & 261 & 255 & 150 & 666 \\
\hline 14 & Kauman & 120 & 94 & 83 & 297 \\
\hline 15 & Pengulu & 113 & 95 & 91 & 299 \\
\hline 16 & Sedagaran & 153 & 147 & 130 & 430 \\
\hline 17 & Srowo & 219 & 251 & 181 & 651 \\
\hline 18 & Golokan & 970 & 930 & 817 & 2717 \\
\hline 19 & $\begin{array}{l}\text { Sabi } \\
\text { Pondok }\end{array}$ & 124 & 130 & 119 & 373 \\
\hline 20 & Wadeng & 1219 & 1282 & 1121 & 3622 \\
\hline 21 & Gedangan & 417 & 457 & 347 & 1221 \\
\hline & Jumlah & 7597 & 8026 & 6269 & 21892 \\
\hline
\end{tabular}

Untuk memperkuat analisa tentang penempatan recloser berdasarkan analisa Statistika Beban dan Populasi maka perlu di buat perhitungan untuk menentukan nilai kegagalan SAIFI terendah dengan melakukan pembagian menjadi beberapa tempat/titik peletakan.

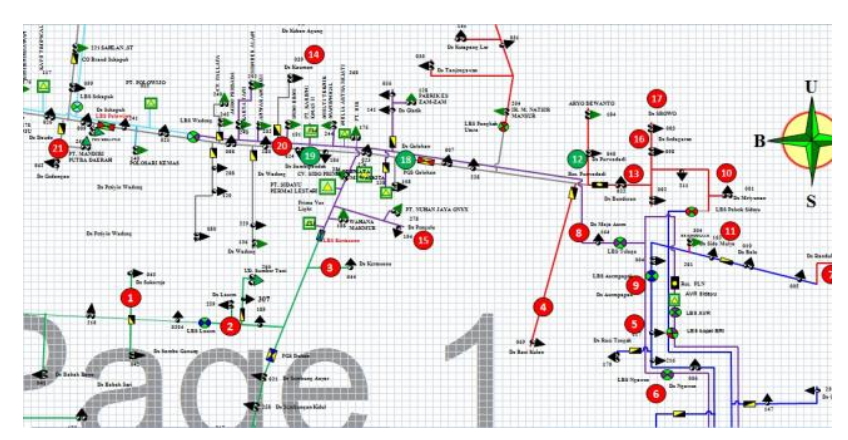

Gambar 3. Single Line Beberapa titik

Setelah melakukan pembagian titik/tempat peletakan recloser berdasarkan analisa beban dan populasi di PT. PLN (Persero) Gresik Rayon Sidayu yang di fokuskan pada kecamatan sidayu maka perlu di pekuat dngan menentukan nilai SAIFI per pembagian titik/tempat dengan melakukan penghitungan tiap titik/tempat :

1. Kondisi jika recloser terpasang di titik 19, gangguan di bawah titik 19

Gangguan Permanen : $N_{\lambda 19}=T_{19} Z_{19} \lambda_{19}$

$$
\begin{aligned}
& =5513.3 .9 \\
& =148851
\end{aligned}
$$

Gangguan Temporer : $N_{\gamma 19}=T_{19} Y_{19} \gamma_{19}$

$$
=5513.3 .11
$$

$=181929$

$N_{19}=N_{\lambda 19}+N_{\gamma 19}=148851+181929$

$$
=330080
$$

$S A I F I=N_{19} / N_{T}=330080 / 21892$

$$
=15,1
$$

2. Kondisi jika recloser terpasang di titik 18 , gangguan di bawah titik 19

Gangguan Permanen : $N_{\lambda 18}=T_{18} Z_{18} \lambda_{19} \underline{Z}_{19}$

$$
=12392.5 .9 .1
$$

$$
=669163
$$

Gangguan Temporer : $N_{\gamma_{18}}=T_{18} Y_{18} \gamma_{19} \underline{Z}_{19}$

$$
\begin{aligned}
& =12392 \cdot 5 \cdot 11 \cdot 1 \\
& =681560
\end{aligned}
$$

$$
\begin{array}{r}
N_{18}=N_{\lambda 18}+N_{\gamma 18}=669163+681560 \\
=1350723
\end{array}
$$

$S A I F I=N_{18} / N_{T}=1350723 / 21892$

$$
=61,7
$$

3. Kondisi jika recloser terpasang di titik 12, gangguan di bawah titik 19

Gangguan Permanen : $N_{\lambda 12}=T_{12} Z_{12} \lambda_{19} \underline{Z}_{18}$

$\underline{\mathrm{Z}_{19}}$

$$
\begin{aligned}
& =16682 \cdot 9 \cdot 9 \cdot 1 \cdot 1 \\
& =1351242
\end{aligned}
$$

Gangguan Temporer : $N_{\gamma_{12}}=T_{12} Y_{12} \gamma_{19} \underline{\mathrm{Z}}_{18}$

$\underline{\mathrm{Z}}_{19}$

$$
\begin{aligned}
& =16682.9 .11 .1 . \\
& =1651518
\end{aligned}
$$

$\begin{aligned} N_{12}=N_{\lambda 12}+N_{\gamma 12}= & 1351242+1651518 \\ & =3002760\end{aligned}$

$S A I F I=N_{12} / N_{T}=1350723 / 21892$

$$
=137,2
$$


dari hasil penjumlahan di atas cukup dapat dapat kita lihat dan kita simpulkan dimana tempat/titik yang memiliki indek kegagalan terendah yaitu tempat/titik 19, dari hasil tersebut juga dapat kita simpulkan bahwa lokasi penempatan recloser yang tepat adalah pada tempat/ titik 19.

Berikut adalah gambar penempatan yang tepat berdasarkan penghitungan indeks kegagalan :

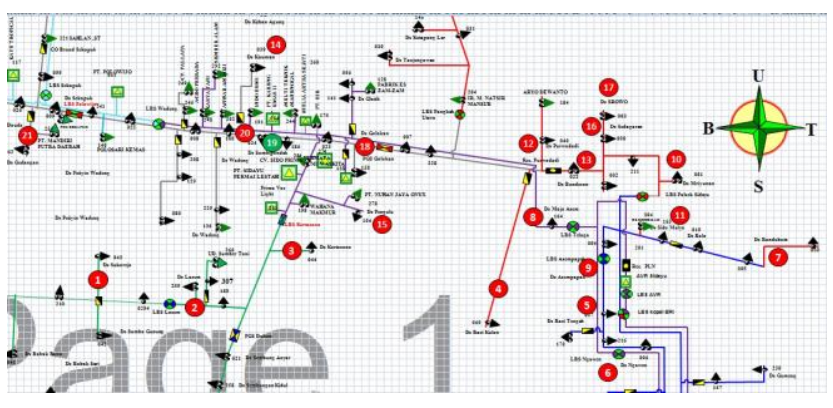

Gambar 4. Single Line Penempatan Tepat

\section{KESIMPULAN}

Berdasarkan hasil penelitian dan pembahasan dapat di simpulkan sebagai berikut:

Dari analisa data tentang penentuan tata letak recloser menggunakan metode penelitian statistika beban dan populasi dapat di ketahui bahwa dengan menganalisa beban dan populasi yang menjadi variable penentuan nilai SAIFI dari recloser dapat di temukan tata letak yang ideal untuk penentuan recloser yaitu titik yang memiliki indeks kegagalan minimum SAIFI yaitu pada titik 19 dengan nilai 15,1 .

Dari analisis data, terbukti bahwa tata letak cukup mempengaruhi kinerja sistem recloser karena sistem recloser sebagai alat proteksi mampu meminimalisir gangguuan yang terjadi di suatu daerah, seperti penelitian ini dengan menganalisa beban dan populasi sebagai variable penghitung nilai indeks kegagalan SAIFI yang dapat menentukan tempat yang tepat dimana resiko ganguuan terhadap pelanggan bisa sangat di minimalkan apabila recloser di pasang.

Dari penelitian menggunakan metode Statistika Beban dan Populasi ini dapat di ketahui bahwa analisa statistika beban dan populasi dapat memunculkan variable-variable yang di butuhkan untuk menentukan nilai
SAIFI dari recloser sehingga dapat di temukan tata letak ideal untuk penempatan recloser yaitu titik yang memiliki indeks kegagalan minimum SAIFI, dalam metode penelitian ini ada 3 titik yang di hitung nilai SAIFInya yaitu titik 19 dengan nilai SAIFI 15,1, titik 18 dengan nilai SAIFI 61,7 dan titik 12 dengan nilai SAIFI 137,2 , dari penghitungan masingmasing titik tersebut dapat di dapatkan hasil indeks gangguan minimum SAIFI yaitu di titik 19.

\section{Daftar Pustaka}

Andik Bintoro, Hazah Berahim, T. Haryono, 2014. Tugas Akhir. Pengaruh kinerja Recloser pada distribusi tegangan transan rumah tangga. Teknik Elektro Universitas Gajah Mada Yogyakarta.

Boediono, Dr \& Wayan Koster, Dr, Ir, MM, 2008. Teori dan Aplikasi Statistika dan Probabilitas. Badan Penerbit A WileyInterscience Publication Anyer, Banten.

Multy Arif, Sony Sunaryo 2013. Tesis. Optimasi Penempatan Recloser Pada Jaringan Distribusi Tenaga Listrik Tdo Bekasap Pt Cpi Dengan Pendekatan Pemograman Non Linear. Magister Managemen Teknologi, Institut Teknologi Sepuluh November Surabaya.

Nur Indah Ariani, Heru Winarno, 2013. Tugas Akhir. Analisis sistem indeks keandalan siste jaringan distribusi udara $20 \mathrm{KV}$ pada penyulang Pandean Lamper 1, 5, 8, 9, 10 di Gardu Induk Pandean Lamper. Teknik Elektro Universitas Diponegoro Semarang, Indonesia

PT. PLN (Persero) Unit Distribusi, Perencanaan Jaringan Distribusi. Data/Informasi/brosur/Rayon Sidayu. Gersik : Sidayu

Radiktyo Nindyo Sumarno, Dr. Ir. Hermawan, DEA, Wahyudi ST.MT, 2009. Optimasi penempatan recloser terhadap keandalan sistem tenaga listrik dengan algoritma genetika. Teknik Elektro Universitas Diponegoro Jln. Prof. Sudharto, Tembalang, Semarang, Indonesia.

Sugiyono, Prof. Dr, 2016. Metode Penelitian Kuantitatif, dan R\&D. Badan Penerbit Alfabeta. 
Sugiyono, Prof. Dr, 2016. Statistika Untuk Penelitian. Badan Penerbit Alfabeta Bandung.

UNISLA, 2017. Pedoman Penulisan Skripsi. Fakultas Teknik Prodi Teknik Elektro. Universitas Islam Lamongan

Wedy Maidien, 2008. Tugas Akhir. Penggunaan recloser dalam mengamankan gangguan hubungan singkat di saluran udara tegangan menengah (SUTM). Teknik Elektro Universitas Mercu Buana Jakarta. 
Halaman ini sengaja dikosongkan 